\title{
Nerve Injury-Induced Neuropathic Pain Causes Disinhibition of the Anterior Cingulate Cortex
}

\author{
Sigrid Marie Blom, ${ }^{1 \star}$ Jean-Pascal Pfister, ${ }^{1 \star}$ Mirko Santello, ${ }^{1}$ Walter Senn, ${ }^{1,2}$ and Thomas Nevian ${ }^{1,2}$ \\ ${ }^{1}$ Department of Physiology and ${ }^{2}$ Center for Cognition, Learning and Memory, University of Bern, 3012 Bern, Switzerland
}

\begin{abstract}
Neuropathic pain caused by peripheral nerve injury is a debilitating neurological condition of high clinical relevance. On the cellular level, the elevated pain sensitivity is induced by plasticity of neuronal function along the pain pathway. Changes in cortical areas involved in pain processing contribute to the development of neuropathic pain. Yet, it remains elusive which plasticity mechanisms occur in cortical circuits. We investigated the properties of neural networks in the anterior cingulate cortex (ACC), a brain region mediating affective responses to noxious stimuli. We performed multiple whole-cell recordings from neurons in layer 5 (L5) of the ACC of adult mice after chronic constriction injury of the sciatic nerve of the left hindpaw and observed a striking loss of connections between excitatory and inhibitory neurons in both directions. In contrast, no significant changes in synaptic efficacy in the remaining connected pairs were found. These changes were reflected on the network level by a decrease in the MEPSC and mIPSC frequency. Additionally, nerve injury resulted in a potentiation of the intrinsic excitability of pyramidal neurons, whereas the cellular properties of interneurons were unchanged. Our set of experimental parameters allowed constructing a neuronal network model of L5 in the ACC, revealing that the modification of inhibitory connectivity had the most profound effect on increased network activity. Thus, our combined experimental and modeling approach suggests that cortical disinhibition is a fundamental pathological modification associated with peripheral nerve damage. These changes at the cortical network level might therefore contribute to the neuropathic pain condition.
\end{abstract}

Key words: anterior cingulate cortex; chronic pain; disinhibition; neuronal network; structural plasticity

\section{Introduction}

Understanding the cellular mechanisms of chronic pain is of high clinical importance, especially because there are no satisfactory treatment strategies for most chronic pain syndromes (Breivik et al., 2006). Tissue or nerve injury results in plastic changes in peripheral nociceptive nerve endings (peripheral sensitization), in the dorsal horn of the spinal cord (central sensitization), as well is in supraspinal and cortical areas, including the somatosensory cortices, the prefrontal cortex, the insular cortex, and the anterior cingulate cortex (ACC) (Neugebauer et al., 2004; Saab, 2012). All of these changes contribute to increased pain sensitivity (Woolf and Salter, 2000; Apkarian et al., 2009). It is hypothesized that chronic pain is a result of failure to reverse the long-term changes along the sensory pain pathways (Basbaum et al., 2009; Costigan et al., 2009).

The ACC is an important area for the interpretation and evaluation of the affective and emotional components of pain (Treede et

Received Aug. 27, 2013; revised Jan. 17, 2014; accepted Feb. 22, 2014.

Author contributions: S.M.B., J.-P.P., M.S., W.S., and T.N. designed research;S.M.B., J.-P.P., and M.S. performed research; S.M.B., J.-P.P., M.S., W.S., and T.N. analyzed data; S.M.B., J.-P.P., M.S., W.S., and T.N. wrote the paper.

This work was supported by the Swiss National Science Foundation Grant PP00P3_128415 to T.N., Grant 31003A_133094 to W.S., and Grant PZ00P3_137200 to J.-P.P. and the Boehringer Ingelheim Fonds to S.M.B. We thank Natalie Nevian for the Neurolucida reconstructions, Hanns-Ulrich Zeilhofer and Alessandra Di Lio for training in CCl surgery and behavioral testing, and Karlijn van Aerde for Igor procedures for spike detection.

The authors declare no competing financial interests.

*S.M.B. and J.-P.P. contributed equally to this work.

Correspondence should be addressed to Dr. Thomas Nevian, Department of Physiology, University of Bern, Bühlplatz 5, CH-3012 Bern, Switzerland. E-mail: nevian@pyl.unibe.ch.

DOI:10.1523/JNEUROSCI.3667-13.2014

Copyright $\odot 2014$ the authors $\quad 0270-6474 / 14 / 345754-11 \$ 15.00 / 0$ al., 1999; Johansen et al., 2001; Qu et al., 2011). It sends prominent projections to other limbic areas (e.g., amygdala) and has widespread connections within the cortex (Pandya et al., 1981; Devinsky et al., 1995; McDonald et al., 1996). The ACC also projects to the periaqueductal gray, an area that plays an important role in descending modulation of pain (Wyss and Sripanidkulchai, 1984; Fields, 2004). Accumulating evidence indicates that plasticity in the ACC is involved in the development of persistent pain (Zhuo, 2008). Particularly, the influence of glutamatergic synaptic plasticity mechanisms in layers 2 and 3 (L2/L3) of the ACC has been highlighted so far (Xu et al., 2008; Li et al., 2010).

Chronic neuropathic pain might also be associated with disinhibition of cortical circuits and impaired GABAergic neurotransmission (Ziemann et al., 1996; Lefaucheur et al., 2006). A balance between cortical excitation and inhibition is essential for normal brain function and signal processing. Inhibitory interneurons in the cortex can strongly control the activity of excitatory neurons influencing the output of a cortical column (Murayama et al., 2009). The cortical disinhibition hypothesis in neuropathic pain is supported by clinical studies showing an analgesic effect of certain patterns of repetitive transcranial magnetic stimulation to the motor cortex that cause activation of inhibitory interneurons (Ziemann et al., 1996; Lefaucheur et al., 2006). This treatment might transiently restore defective intracortical inhibition. Furthermore, changes in GABA content have recently been described in the thalamus, anterior insula, and ACC of chronic pain patients (Foerster et al., 2012; Henderson et al., 2013). Thus, disinhibition of cortical microcircuits might be a 
Table 1. Connectivity parameters ${ }^{a}$

\begin{tabular}{cccclc}
\hline & & $A(\mathrm{mV})$ & $\tau_{D}(\mathrm{~ms})$ & $u$ & $p$ \\
\hline Sham & & & & & \\
$\mathrm{El}$ & $\phi_{E I}^{+}$ & 6.52 & 265 & 0.219 & \\
$\mathrm{El}$ & $\bar{\phi}_{E I}^{-}$ & 5.82 & 266 & 0.222 & $22 / 81$ \\
$\mathrm{El}$ & $\phi_{E I}^{-}$ & 5.12 & 269 & 0.227 & \\
$\mathrm{IE}$ & $\phi_{I E}^{+}$ & 0.77 & 74 & 0.436 & \\
$\mathrm{IE}$ & $\bar{\phi}_{I E}$ & 0.97 & 80 & 0.463 & $17 / 71$ \\
$\mathrm{IE}$ & $\phi_{I E}^{-}$ & 1.17 & 83 & 0.482 & \\
$\mathrm{EE}$ & $\phi_{E E}^{+}$ & 0.56 & 52 & 0.4 & \\
$\mathrm{EE}$ & $\bar{\phi}_{E E}$ & 1.03 & 84 & 0.18 & $5 / 247$ \\
$\mathrm{EE}$ & $\phi_{E E}^{-}$ & 2.23 & 234 & 0.068 & \\
$\mathrm{CCl}$ & & & & & \\
$\mathrm{El}$ & $\phi_{E I}^{+}$ & 4.52 & 296 & 0.341 & \\
$\mathrm{El}$ & $\bar{\phi}_{E I}$ & 3.65 & 287 & 0.323 & $10 / 76$ \\
$\mathrm{El}$ & $\phi_{E I}^{-}$ & 2.79 & 273 & 0.292 & \\
$\mathrm{IE}$ & $\phi_{I E}^{+}$ & 1.12 & 82 & 0.345 & \\
$\mathrm{IE}$ & $\bar{\phi}_{I E}$ & 2.35 & 133 & 0.241 & $6 / 71$ \\
$\mathrm{IE}$ & $\phi_{I E}^{-}$ & 3.41 & 158 & 0.219 & \\
$\mathrm{EE}$ & $\phi_{E E}^{+}$ & 0.91 & 187 & 0.192 & \\
$\mathrm{EE}$ & $\bar{\phi}_{E E}$ & 0.84 & 215 & 0.164 & $4 / 161$ \\
$\mathrm{EE}$ & $\phi_{E E}^{-}$ & 0.77 & 262 & 0.131 & \\
\hline
\end{tabular}

${ }^{a}$ Fitted short-term plasticity parameters $\phi=\left(A, \tau_{D}, u\right)$ on the mean EPSP responses $(\bar{\phi})$, mean $-\operatorname{SEM}\left(\phi^{-}\right)$, and mean $+\operatorname{SEM}\left(\phi^{+}\right)$(data from Fig. $\left.5 D, E, F\right)$. The fitting is done for synapses from excitatory to inhibitory neurons (El), from inhibitory neurons to excitatory neurons (IE), and the recurrent excitatory connections (EE) for both sham and $\mathrm{Cl}$ conditions. The last column indicates the connection probability.

Table 2. Fitted parameters for the $\mathrm{Fl}$ curves for excitatory neurons (E) and inhibitory neurons (I) in the sham and $\mathrm{CCl}_{\text {conditions }}{ }^{a}$

\begin{tabular}{|c|c|c|c|c|c|c|}
\hline & $\beta\left(\mathrm{pA}^{-1}\right)$ & $\theta(\mathrm{pA})$ & $\gamma(\mathrm{pA})$ & $f_{\text {max }}(\mathrm{Hz})$ & $R(\mathrm{M} \Omega)$ & $\tau(\mathrm{ms})$ \\
\hline \multicolumn{7}{|l|}{ Sham } \\
\hline \multicolumn{7}{|l|}{$\mathrm{E}$} \\
\hline$\psi_{E}^{+}$ & 0.0266 & 130 & 369 & 82.2 & \multirow{3}{*}{$\begin{array}{l}56.8 \\
( \pm 2.4)\end{array}$} & \multirow{3}{*}{$\begin{array}{l}11.9 \\
( \pm 0.9)\end{array}$} \\
\hline $\bar{\psi}_{E}$ & 0.0261 & 137 & 355 & 79.5 & & \\
\hline$\psi_{E}^{-}$ & 0.0257 & 144 & 341 & 76.8 & & \\
\hline \multicolumn{7}{|l|}{$1^{+L}$} \\
\hline$\psi_{I}^{+}$ & 0.0108 & 534 & 36 & 400 & \multirow{3}{*}{$\begin{array}{l}49.4 \\
( \pm 2.9)\end{array}$} & \multirow{3}{*}{$\begin{array}{c}5.5 \\
( \pm 0.3)\end{array}$} \\
\hline $\bar{\psi}_{I}$ & 0.0109 & 517 & 49 & 400 & & \\
\hline$\psi_{I}^{-}$ & 0.0111 & 507 & 62 & 400 & & \\
\hline \multicolumn{7}{|l|}{$\mathrm{CCl}$} \\
\hline \multicolumn{7}{|l|}{$E$} \\
\hline$\psi_{E}^{+}$ & 0.0225 & 135 & 231 & 71.9 & \multirow{4}{*}{$\begin{array}{l}67.1 \\
( \pm 3.5)\end{array}$} & \multirow{3}{*}{$\begin{array}{l}11.2 \\
( \pm 0.2)\end{array}$} \\
\hline $\bar{\psi}_{E}$ & 0.0222 & 142 & 225 & 69.6 & & \\
\hline$\psi_{E}^{-}$ & 0.0221 & 148 & 220 & 67.3 & & \\
\hline \multicolumn{6}{|l|}{$I^{T E}$} & \\
\hline$\psi_{I}^{+}$ & 0.0106 & 465 & 51 & 400 & \multirow{3}{*}{$\begin{array}{l}49.7 \\
( \pm 3.0)\end{array}$} & \multirow{3}{*}{$\begin{array}{c}4.8 \\
( \pm 0.3)\end{array}$} \\
\hline $\bar{\psi}_{I}$ & 0.011 & 450 & 68 & 400 & & \\
\hline$\psi_{I}^{-}$ & 0.0118 & 434 & 88 & 400 & & \\
\hline
\end{tabular}

${ }^{a}$ The mean $(\bar{\psi})$, mean + SEM $\left(\psi^{+}\right)$, and mean - SEM $\left(\psi^{-}\right)$FI curves are fitted as well as the input resistance $(R)$ and the membrane time constant $\left(t_{m}\right)$. Values in parentheses are SEM.

fundamental mechanism at the basis of pathological changes in the brain (Letzkus et al., 2011).

We investigated whether nerve damage induced by chronic constriction injury (CCI) of the sciatic nerve, a well-established model for neuropathic pain, caused changes in L5 of the ACC both at the cellular and the network level. We examined whether nerve injury modified the intrinsic excitability of ACC neurons as well as the synaptic properties between locally connected neurons (Xu et al., 2008; Zhuo, 2008). Furthermore, because postsynaptic dendritic spines on tuft dendrites of L5 pyramidal neurons in the somatosensory cortex are rapidly rewired after nerve injury (Kim and Nabekura, 2011), we hypothesized that functional connectivity in the L5 ACC neuronal network might be affected by peripheral lesions. Finally, we constructed a model of the local

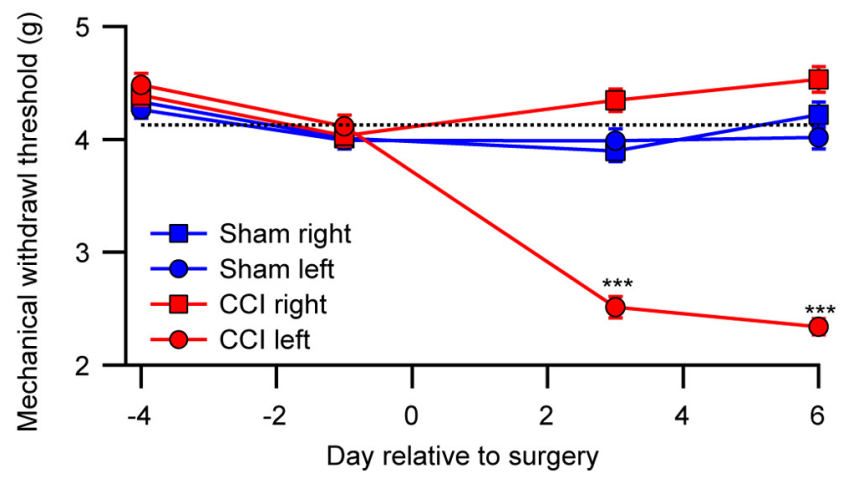

Figure 1. Average paw withdrawal thresholds in response to electronic von Frey filament testing. CCl animals developed mechanical hyperalgesia reflected in a decrease in the mechanical withdrawal threshold on the left (injured) side over time (red circles), whereas the withdrawal threshold on the right side did not change (red squares). Sham operated animals did not show any mechanical sensitization on either side (blue symbols). Error bars indicate SEM. $n=$ 64 (sham) and $n=56$ (CCl). ${ }^{* *} p<0.001$.

microcircuit to study the effective input-output function of the pathologically modified network based on our experimental findings.

\section{Materials and Methods}

Chronic constriction injury. All experiments were approved by the veterinary office of the canton of Bern, Switzerland. Adult (8-12 weeks old), male, C57BL/6 mice were used for the experiments. CCI followed the procedure by Bennett and Xie (1988). Mice were anesthetized with isoflurane, an incision was made in the left thigh, and the sciatic nerve was exposed. Three loose ligatures $1 \mathrm{~mm}$ apart were then made around the nerve using 5-0 Sofsilk tread (US Surgicals). The control group underwent sham surgery where the left sciatic nerve was exposed but not further manipulated. The incision was closed using 4-0 coated VICRYL rapid suture (Ethicon). The animals did not receive postoperative analgesics. A total of 120 animals (64 sham and 56 CCI) were used in the investigations.

Electronic von Frey testing. Mechanical hyperalgesia was assessed using an Electronic von Frey anesthesiometer (IITC Life Science). Mice were placed individually in Plexiglas test compartments with a wire mesh bottom and allowed to habituate for $\sim 30 \mathrm{~min}$. The von Frey filament was applied to the midplantar surface of the hindpaw 6 times for each hindpaw per testing session.

Brain slice preparation. Seven to 14 days after surgery, mice were anesthetized with isoflurane and decapitated, and the brain was quickly removed and transferred to ice-cold oxygenated solution containing 65 mм NaCl, $2.5 \mathrm{~mm} \mathrm{KCl}, 1.25 \mathrm{~mm} \mathrm{NaH} \mathrm{PO}_{4}, 25 \mathrm{~mm} \mathrm{NaHCO}_{3}, 7 \mathrm{~mm}$ $\mathrm{MgCl}_{2}, 0.5 \mathrm{~mm} \mathrm{CaCl}_{2}, 25 \mathrm{~mm}$ glucose, and $105 \mathrm{~mm}$ sucrose; $300-\mu \mathrm{m}-$ thick coronal slices were cut from the tissue block with a vibratome (Microm) and kept in an ACSF containing $125 \mathrm{~mm} \mathrm{NaCl}, 2.5 \mathrm{~mm} \mathrm{KCl}$, $1.25 \mathrm{~mm} \mathrm{NaH}_{2} \mathrm{PO}_{4}, 25 \mathrm{~mm} \mathrm{NaHCO}_{3}, 1 \mathrm{~mm} \mathrm{MgCl}, 2 \mathrm{mMCaCl}_{2}$, and 25 $\mathrm{mm}$ glucose at $34^{\circ} \mathrm{C}$ for $45 \mathrm{~min}$ and then at room temperature until use. We made coronal slices from bregma $1.70 \mathrm{~mm}$ to zero and recorded from neurons in the cingulate cortex, area 1 and 2 as defined by (Paxinos and Watson, 1997). All brain slices were prepared from mice that were also tested for mechanical hyperalgesia.

Electrophysiology and data analysis. All experiments were performed at $34^{\circ} \mathrm{C}-37^{\circ} \mathrm{C}$. For recording, slices were transferred to a recording chamber perfused with oxygenated ACSF solution (same as above). Whole-cell recordings were made from L5 pyramidal neurons and interneurons on the contralateral side of the nerve injury. Cells were identified using infrared gradient contrast video microscopy. Recording electrodes with a resistance of 4-9 $\mathrm{M} \Omega$ were made using borosilicate glass capillaries. Recordings were performed using Dagan BVC-700A amplifiers (Dagan), and data were acquired with an ITC-16 board (Instrutech) and using Igor software (Wavemetrics). The intracellular solution, if not otherwise stated, contained $130 \mathrm{~mm}$ potassium gluconate, $5 \mathrm{~mm} \mathrm{KCl}, 10 \mathrm{~mm}$ 
HEPES, $10 \mathrm{~mm}$ sodium phosphocreatine, $4 \mathrm{~mm}$ Mg-ATP, 0.3 mм Na-GTP, and $0.2 \%$ biocytin, pH 7.3 with $\mathrm{KOH}$. To find the threshold for action potential (AP) generation, the cells were depolarized by injection of $600 \mathrm{~ms}$ pulses of increasing intensity (10 pA increments). The same protocol was used to determine the firing rate versus current curves.

To determine the input resistance, the cells were hyperpolarized by injection of a $-300 \mathrm{pA}$ current pulse of $600 \mathrm{~ms}$ duration. The steadystate voltage deflection as a function of the response to long-current injection was then fitted to the following quadratic equation:

$$
\Delta V=R_{N, 0} \Delta I+C_{A R} \Delta I^{2}
$$

where $R_{N, 0}$ is the slope of the curve at $I=0$ (i.e., input resistance at resting membrane potential) and $C_{A R}$ is the coefficient of anomalous rectification. Unitary synaptic connections were examined by patching up to four cells simultaneously and eliciting short regular trains (8 pulses) of APs at $30 \mathrm{~Hz}$ followed by one AP $500 \mathrm{~ms}$ after the initial AP in the burst in one cell while recording the activity in the other cells. The protocol was repeated 50 times at 0.1 $\mathrm{Hz}$, and the responses were averaged. When testing for excitatory connections, the activity was recorded at the resting membrane potential, whereas the cells were depolarized to -55 $\mathrm{mV}$ by injection of current when testing for inhibitory connections. Miniature excitatory postsynaptic currents (mEPSCs) were recorded from fast-spiking (FS) interneurons in voltage clamp at a membrane potential of $-70 \mathrm{mV}$ in the presence of $1 \mu \mathrm{M}$ TTX and $1 \mu \mathrm{M}$ 4-[6-imino-3(4-methoxyphenyl)pyridazin-1-yl] butanoic acid hydrobromide (GABAzine).

Miniature inhibitory postsynaptic currents (mIPSCs) were recorded from pyramidal cells clamped at a membrane voltage of $-70 \mathrm{mV}$ in the presence of $1 \mu \mathrm{M}$ TTX, $10 \mu \mathrm{M}$ CNQX, and $50 \mu \mathrm{M}$ APV using an intracellular solution that changed the reversal potential for chloride to 0 $\mathrm{mV}$. This intracellular solution contained 135 mM KCl, 10 mM HEPES, 10 mm sodium phosphocreatine, 4 mм Mg-ATP, $0.3 \mathrm{~mm} \mathrm{Na-GTP}$, and $0.2 \%$ biocytin, pH 7.3 with $\mathrm{KOH}$.

Electrophysiological data were analyzed using custom-written procedures in Igor Pro (Wavemetrics). The short-term dynamics of postsynaptic potentials was analyzed following the Tsodyks-Markram model (Tsodyks and Markram, 1997). mEPSCs/mIPSCs were analyzed using the Mini Analysis Program (Synaptosoft).

Statistical analysis. Statistical analysis was performed using unpaired two-sided Student's $t$ test (for single comparisons), two-way ANOVA with Bonferroni's post hoc test (for multiple comparisons), or Fisher's exact test (for analysis of contingency tables). Statistical significance was asserted for $p<0.05$. Data are presented as mean \pm SEM.

Model. We consider a network composed of a pool E of $N_{E}=800$ (excitatory) pyramidal neurons and a pool I of $N_{I}=200$ (inhibitory) fast spiking interneurons (see Fig. $7 A$ ) and propose here a simple mean field description. Let $r_{\mathrm{E}}$ (resp. $r_{\mathrm{I}}$ ) denote the average firing rate of the excitatory (reps. inhibitory) neurons. Each neuron from the excitatory pool is connected with probability $p_{\mathrm{EI}}$ to an inhibitory neuron such that the expected number of connections from the excitatory pool to the inhibitory pool is given by $p_{\mathrm{EI}} N_{\mathrm{E}}$. Similarly, $p_{\mathrm{EI}}$ denotes the connection probability from the pool I to the pool E. Finally, we assume that the pool E is recurrently connected with a connection probability of $p_{\mathrm{EE}}$. We further 0.05 . $^{* *} p<0.01{ }^{* * *} p<0.001$.
D

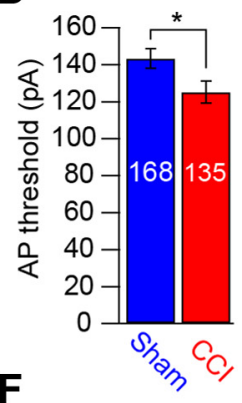

E
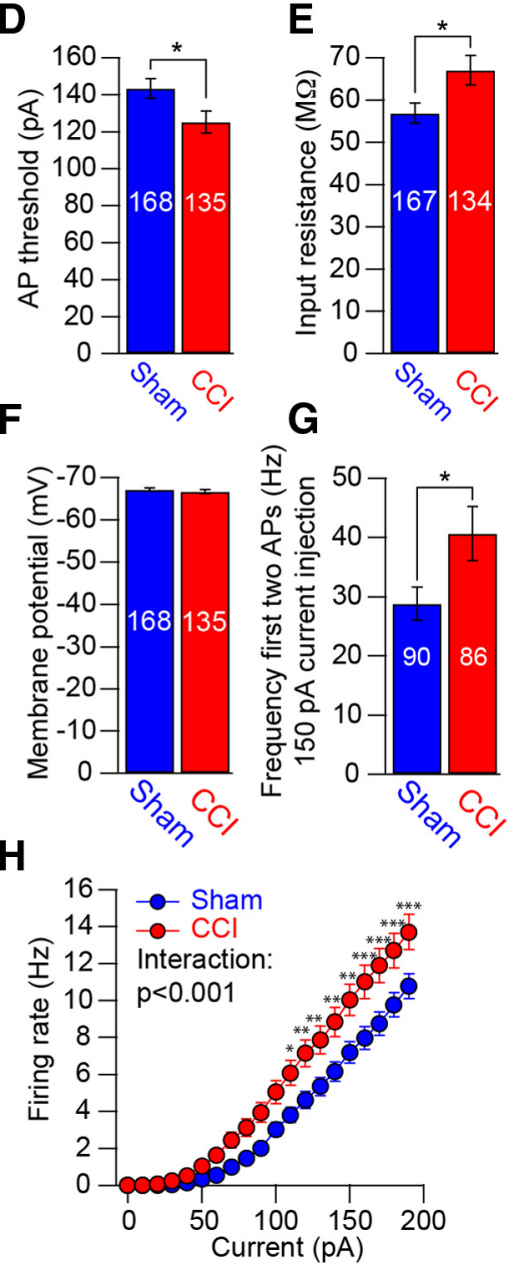

Figure 2. Nerve injury increases the intrinsic excitability of $L 5$ pyramidal neurons in the anterior cingulate cortex. $\boldsymbol{A}$, Recon-

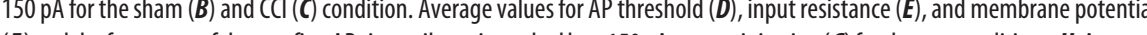
ANOVA followed by Bonferroni's post hoc test in $\boldsymbol{H}$. Numbers in bar graphs indicate number of cells. Error bars indicate SEM. ${ }^{*} p<$

assume that synapses are depressing such that the effective connection strength between two pools is rate-dependent. Let $w_{\mathrm{EI}}=c_{\mathrm{EI}} x_{\mathrm{EI}}$ be the effective weight from the excitatory pool to the inhibitory pool and $x_{\mathrm{EI}}$ the expected resource variable (fraction of available vesicles), which depends on the presynaptic firing rate $r_{\mathrm{E}}$. Similarly, the effective weight from inhibitory neurons to excitatory neurons is given by $w_{\mathrm{IE}}=c_{\mathrm{IE}} x_{\mathrm{IE}}$ and finally, the effective self-connection of the excitatory pool is given (see below for the derivation of the constants $c_{\mathrm{EI}}, c_{\mathrm{IE}}, c_{\mathrm{EE}}$ ). For a presynaptic (Poisson) rate $r_{a}$, the dynamics of the average resource variable $x_{a b}$ for synapses that connect pool $a$ to pool $b$ yields (Tsodyks and Markram, 1997) as follows:

$$
\dot{x}_{a b}=\frac{1-x_{a b}}{\tau_{D, a b}}-u_{a b} x_{a b} r_{a} \quad(a, b) \in\{\mathrm{EI}, \mathrm{IE}, \mathrm{EE}\}
$$

Let $f_{\mathrm{E}}(I)$ denote the F-I curve for pyramidal neurons (see Fig. $7 B$ ) and expressed as follows:

$$
f_{\mathrm{E}}(I)=\frac{f_{\max , \mathrm{E}} h_{\mathrm{E}}(I)}{\gamma_{\mathrm{E}}+h_{\mathrm{E}}(I)}
$$

where $h_{\mathrm{E}}(I)=\frac{1}{\beta_{\mathrm{E}}} \log \left(1+\exp \left(\beta_{\mathrm{E}}\left(\mathrm{I}-\theta_{\mathrm{E}}\right)\right)\right)$ is a smooth rectified linear function. A standard sigmoidal function does not reproduce well the data 
because the slope increases quickly and then decreases slowly. Similarly, let $f_{\mathrm{I}}(I)$ denote the F-I curve for fast spiking neurons (see Fig. 7C). Because for this F-I curve the saturation does not appear in the measured range, we assumed a maximal firing rate of $f_{\max , \mathrm{I}}=400 \mathrm{~Hz}$. The dynamics of the population of excitatory and inhibitory neurons can be written as follows:

$$
\begin{gathered}
\tau_{\mathrm{E}} \dot{r}_{\mathrm{E}}=-r_{\mathrm{E}}+f_{\mathrm{E}}\left(w_{\mathrm{EE}} r_{\mathrm{E}}-w_{\mathrm{IE}} r_{\mathrm{I}}+I_{\mathrm{E}}\right) \\
\tau_{\mathrm{I}} \dot{r}_{\mathrm{I}}=-r_{\mathrm{I}}+f_{\mathrm{I}}\left(w_{\mathrm{EI}} r_{\mathrm{E}}\right)
\end{gathered}
$$

where $\tau_{\mathrm{E}}\left(\operatorname{resp} . \tau_{\mathrm{I}}\right)$ denotes the membrane time constant of the excitatory (reps. inhibitory) neurons, and $I_{\mathrm{E}}$ denotes the external current applied to the pool of excitatory neurons. Overall the dynamical system we are considering contains five differential equations: two for the pools of neurons (see Eqs. 4 and 5) and three for the dynamical synapses (see Eq. 2). All parameters (except $N_{\mathrm{E}}$ and $N_{\mathrm{I}}$ ) were fit to the data by minimizing mean square errors.

Estimation of the effective weight. The simplest description of the membrane potential $v$ of the postsynaptic neuron is given by an integrate-andfire type of model:

$$
\tau \dot{v}=-v+R I
$$

where $t$ is the membrane time constant, $R$ is the input resistance, and $I$ is the input current. Here we do not specify how the spiking occurs (e.g., there could be some noisy threshold). Indeed, we will assume that spiking mechanism is such that it is consistent with the observed frequency output (F-I) curve (see Fig. $7 A, B$; Eq. 2).

In the absence of short-term plasticity, a single presynaptic action potential at time $t_{0}$ acts as a Dirac input current $I(t)=q \delta\left(t-t_{0}\right)$ with an associated charge $q$. Using Equation 6, this gives rise to a depolarization $\Delta v=\frac{R q}{\tau}$. For a depressing synapse, the charge entering the postsynaptic cell is not constant but depends on the presynaptic spiking history. So this charge at a time of a spike $t$ is given by $q(t)=q_{0} u x(t)$ where $u$ is the utilization fraction and $x(t)$ is the fraction of available resources at time $t$ and is governed by the following dynamics:

$$
\dot{x}=\frac{1-x(t)}{\tau_{\mathrm{D}}}-u x(t-\epsilon) S(t)
$$

with $S(t)=\Sigma_{t f} \delta\left(t-t_{f}\right)$ is the presynaptic delta spike train and $\epsilon$ is an arbitrary small positive constant (to respect causality). Under the assumption of Poisson firing with $r(t)=\langle S(t)\rangle$, the expected resource $\langle x\rangle$ (denoted as $x$ from here on) obeys the following dynamics:

$$
\dot{x}=\frac{1-x}{\tau_{\mathrm{D}}}-u x(t-\epsilon) r(t)
$$

The expected stationary input current $I(t)=q_{0} u x(t)$ can be written as $I(t)=n R^{-1} A_{\max } \tau x(t)=: w(t) r(t)$ where $n$ indicates the number of convergent inputs (all of them are assumed to have an average firing rate of $r$ ) and where we used the fact that the maximal EPSP amplitude $A_{\max }$ can be expressed as $A_{\max }=R q_{0} u / \tau$ by using the above expressions for $\Delta v$ and $q(t)$. So the effective connection from population $a \in\{\mathrm{E}, \mathrm{I}\}$ to $b \in\{\mathrm{E}, \mathrm{I}\}$ is given as follows:

$$
w_{a b}(t)=p_{a b} N_{a} R_{b}^{-1} A_{a b} \tau_{b} x_{a b}(t)=: c_{a b} x(t)
$$

Uncertainty estimation for the effective transfer function. In Figure $7 D$, we show that the response of the excitatory neurons (when embedded in the network) responds stronger to an external input current in the CCI condition than in the sham condition. This is true for the average estimated parameters (Fig. 4F, dashed line). However, it might be that the uncertainty in the measured parameters is so large that we cannot substantiate the above claim. We want to show here that this is not the case.

Let $N=1000$ be the total number of neurons considered and $\rho_{\mathrm{E}}=0.8$ be the fraction of pyramidal neurons and $\left(1-\rho_{\mathrm{E}}\right)$ the fraction of interneurons. Let $\Theta=\left\{\Gamma_{\mathrm{E}}, \Gamma_{\mathrm{I}}, \Lambda_{\mathrm{EE}}, \Lambda_{\mathrm{IE}}, \Lambda_{\mathrm{EI}}\right\}$ be the set of all parameters where $\Gamma_{a}=\left\{R_{a}, \tau_{m, a}, \psi_{a}\right\}$ denotes the set of parameters for the pool of neurons
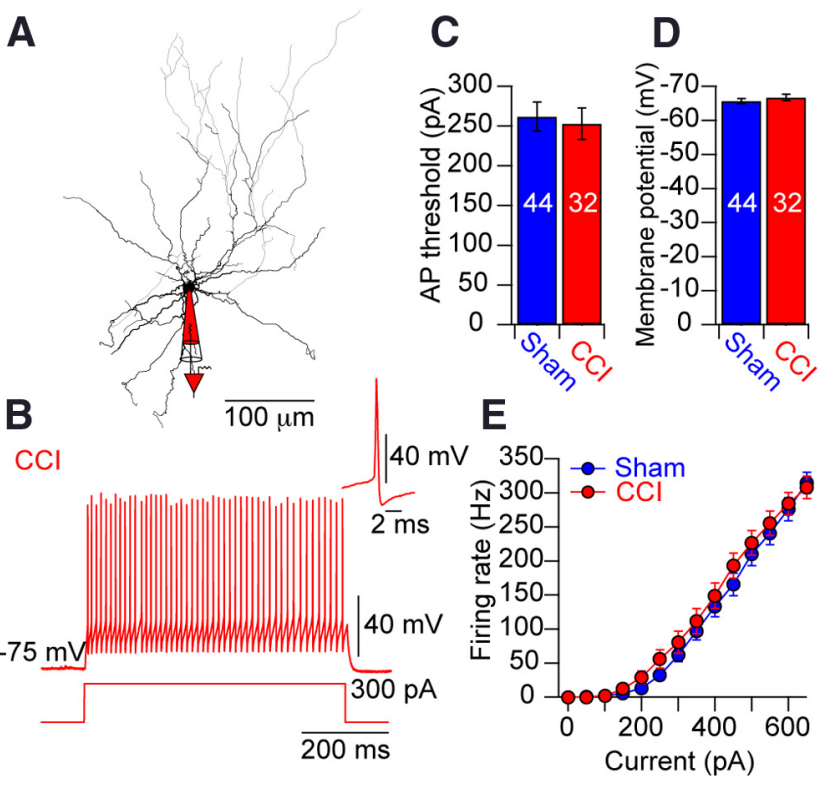

Figure 3. Nerve injury does not change the intrinsic excitability of $L 5$ fast-spiking interneurons. $\boldsymbol{A}$, Reconstruction of a biocytin-filled $L 5$ interneuron. $\boldsymbol{B}$, Example of an evoked response elicited by $700 \mathrm{~ms}$ current injection of $150 \mathrm{pA}$ for the $\mathrm{CCl}$ condition. Magnification of a single AP is shown in the inset. Average values for AP threshold $(\boldsymbol{C})$ and membrane potential (D) for the two conditions. $\boldsymbol{E}$, Average F-I curves for the two conditions. Statistical significance was determined by two-tailed Student's $t$ test in $\boldsymbol{C}$ and $\boldsymbol{D}$ and by two-way ANOVA followed by Bonferroni's post hoc test in $\boldsymbol{E}$. Numbers in bar graphs indicate number of cells. Error bars indicate SEM.

$a \in\{\mathrm{E}, \mathrm{I}\}$ and $\psi_{\mathrm{E}}=\left\{\beta_{\mathrm{E}}, \theta_{\mathrm{E}}, \gamma_{\mathrm{E}}, f_{\max , \mathrm{E}}\right\}$ denotes the set of parameters for the F-I curve of the pyramidal neurons and $\psi_{\mathrm{I}}=\left\{\beta_{\mathrm{I}}, \theta_{\mathrm{I}}, \gamma_{\mathrm{I}}, f_{\max , \mathrm{I}}\right\}$ those for the interneurons. Let $\Lambda_{a b}=\left\{p_{a b}, \phi_{a b}\right\}$ denote the set of parameters for the connection from pool $a$ to pool $b$ where $\phi_{a b}=\left(\tau_{D, a b}, u_{a b}, A_{a b}\right)$ denotes the STP parameters (Table 1).

To show that the effective F-I curve is different for the sham and CCI conditions, we generated thousand parameter sets for the sham condition: i.e., $\Theta_{i}^{\text {sham }}, i=1, \ldots, 1000$ and thousand for the CCI condition: $\Theta_{i}^{\mathrm{CCI}}, i=1, \ldots, 1000$. We then calculate the effective F-I curve for each of those parameter set and display the first and third quartiles of the distribution over F-I curves (Fig. 7 F, G, shaded area). How those parameter sets are generated is described in the following subsections.

F-I curve $(\psi)$ : for both the pyramidal neuron $(a=E)$ and the interneurons $(a=I)$, we fitted the mean F-I curve to get $\bar{\psi}_{a}$, the mean + SEM $\left(\psi_{a}^{+}\right)$as well as the mean $-\operatorname{SEM}\left(\psi_{a}^{-}\right)$(see Figure $7 B, C$ and Table 2). Sample F-I curves are obtained by choosing the F-I parameters $\Psi_{a}$ as $\psi_{a}=\lfloor\epsilon\rfloor_{+}\left(\psi_{a}^{+}-\bar{\psi}_{a}\right)+\lfloor-\epsilon\rfloor_{+}\left(\psi_{a}^{-}-\bar{\psi}_{a}\right)$ where $\epsilon$ is drawn from a Gaussian distribution, i.e., $\epsilon \sim \mathcal{N}(0,1)$ and $\lfloor x\rfloor_{+}$denotes a linear rectification, i.e., when $x>0,\lfloor x\rfloor_{+}=x$; otherwise, $\lfloor x\rfloor_{+}=0$.

STP parameters $(\phi)$ : the sampling of the STP parameters $\phi=\left(A, \tau_{D}, u\right)$ are done in the same way as for the F-I curve because the uncertainty in each of those parameters is correlated, i.e., $\phi_{a b}=\lfloor\epsilon\rfloor_{+}\left(\phi_{a b}^{+}-\bar{\phi}_{a b}\right)+\lfloor-\epsilon\rfloor_{+}\left(\phi_{a b}^{-}-\bar{\phi}_{a b}\right)$ where $\epsilon$ is also drawn from a unit variance Gaussian distribution (see Table 2).

Connection probability $(p)$ : in the model we use the parameters $p_{E I}$, $p_{I E}$, and $p_{E E}$, which denote the probability to find a connection between a given population to another. The mean parameter is simply estimated as the empirical mean, i.e., $p=k / m$, where $k$ is the number of connections found and $m$ denotes the number of connections tested. Because the Beta distribution is the conjugate prior of the Bernoulli distribution, we can simply sample from a Beta distribution, i.e., $p \sim \operatorname{Beta}(k, m-k)$.

All other (positive) parameters: all other parameters (i.e., $R$ and $\tau$ ) are sampled from a Gamma distribution because they are all positive. Since the mean of a Gamma distribution $\operatorname{Gamma}(k, \theta)$ is given by $\mu=k \theta$ and the variance by $\sigma^{2}=k \theta^{2}$, we can invert those relations and obtain $k=\mu^{2} / \sigma^{2}$ and $\theta=\sigma^{2} / \mu$. Therefore, those positive parameters (i.e., $R, \tau$ ) are individu- 


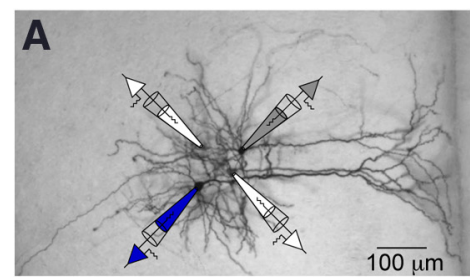

B

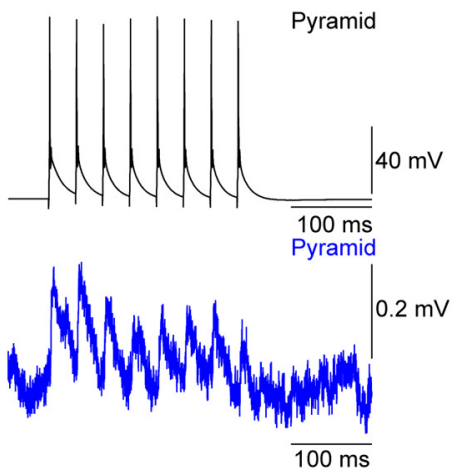

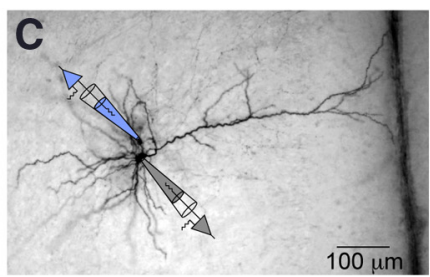

D
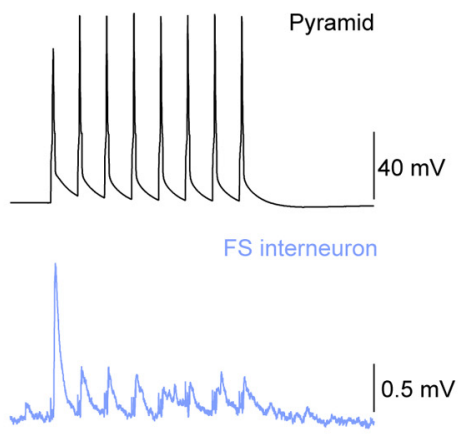
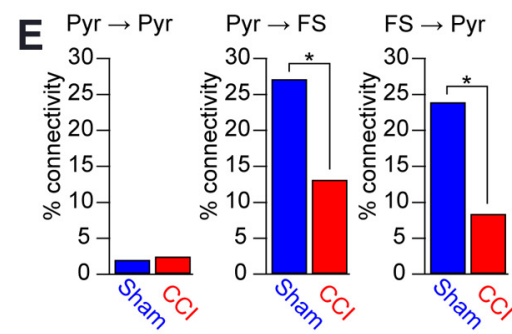

FS interneuron

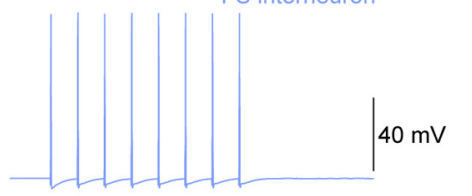

Pyramid

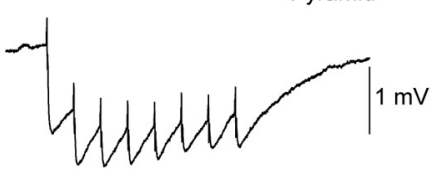

Figure 4. Nerve injury changes the neuronal connectivity pattern in $L 5$ of the $A C C$. $A$, Biocytin staining of pyramidal neurons. $B$, Example voltage traces showing presynaptic and postsynaptic recordings for a pyramidal cell-pyramidal cell connection. C, Biocytin staining of a connected pyramidal cell and a FS interneuron. D, Example voltage traces showing presynaptic and postsynaptic recordings for a pyramidal cell-FS interneuron connection (left) and FS interneuron-pyramidal cell connection (right). $\boldsymbol{E}$, Connectivity probability for pyramidal cell-pyramidal cell connections (left), pyramidal cell-FS interneuron connections (middle), and FS interneuron-pyramidal cell connections (right). ${ }^{*} p<0.05$.

ally sampled from $\operatorname{Gamma}\left(\mu^{2} / \sigma^{2}, \sigma^{2} / \mu\right)$ where $\mu$ denotes the empirical mean of that parameter and $\sigma^{2}$ its empirical variance.

Effect of each model parameter. Figure $8 A, B$ describes the effect of each model parameter. We grouped some parameters together (e.g., the parameters describing the F-I curve $(\psi)$ or the short-term plasticity parameters $(\phi)$ ) since they are simultaneously estimated from a set of measurements thereby inducing correlations. Let $F(\Theta)$ denote the firing rate of the excitatory neurons (when embedded in the network) for a given parameter set $\Theta$ and for a given input current $I$. The relative effect $\Delta(q, I)$ of a given parameter (or group of parameters) $q$ for a given input current $I$ is estimated as follows:

$$
\Delta(q, I)=\frac{\mathrm{F}\left(\Theta^{\text {sham } \backslash \mathrm{q}}, I\right)-\mathrm{F}\left(\Theta^{\text {sham }}, I\right)}{\mathrm{F}\left(\Theta^{\mathrm{CCI}}, I\right)-\mathrm{F}\left(\Theta^{\text {sham }}, I\right)}
$$

where $\Theta^{\text {shamlq }}$ denotes the sham parameter set with parameter $q$ being replaced by the corresponding one from the CCI dataset. The relative effect of each parameter is displayed in Figure $5 \mathrm{~A}$ for an input current of $300 \mathrm{pA}$ and in Fig. $8 B$ for 150 pA. Error bars are obtained by generating hundred parameter sets $\Theta^{\text {shamlq }}$ where the parameter $q$ is taken from its CCI distribution (see above). The error bar denotes the first and third quartile of the obtained distribution over $\Delta$.

\section{Results}

\section{Intrinsic excitability is increased in L5 pyramidal neurons} after chronic constriction injury of the sciatic nerve

To evaluate whether peripheral nerve damage caused changes in the L5 neuronal network of the ACC, we injured the left sciatic nerve by CCI surgery in adult mice. To follow the development of mechanical pain sensitivity, we performed electronic von Frey testing twice before the surgery and on days 3 and 6 after surgery (Fig. 1). CCI operated mice showed a significantly lower mechanical withdrawal threshold on their left hindpaw compared with their right hindpaw on days 3 and 6 , indicating that the animals had developed mechanical hyperalgesia (Bennett and Xie, 1988). In contrast, animals that had undergone sham surgery did not develop mechanical sensitization.
To investigate whether CCI surgery changed the intrinsic excitability of L5 pyramidal neurons in the contralateral ACC, we compared the current threshold for the generation of APs in cells from sham and CCI animals. L5 pyramidal neurons in slices from CCI animals had a significantly lower AP threshold than cells in slices taken from sham animals (sham: $143.45 \pm 5.21 \mathrm{pA}, n=$ 168; CCI: $125.33 \pm 6.01 \mathrm{pA}, n=135, p<0.05$; Fig. $2 A-D$ ). This change in AP threshold was accompanied by a significant increase in the input resistance in CCI compared with sham animals (sham: $56.85 \pm 2.39 \mathrm{M} \Omega, n=167$; CCI: $67.06 \pm 3.48 \mathrm{M} \Omega$, $n=134, p<0.05 ;$ Fig. $2 E$ ). CCI surgery did not affect the resting membrane potential $V_{\mathrm{m}}$ (sham: $-67.13 \pm 0.35 \mathrm{mV}, n=168$; CCI: $-66.65 \pm 0.46 \mathrm{mV}, n=135, p=0.4$; Fig. $2 F)$. We also compared input-output curves and found that CCI surgery induced a left shift in the input current to AP frequency curves (F-I curves) with a significantly increased firing rate over a wide range of current injections (Fig. 2H). Moreover, the two first APs in a spike train (elicited by $150 \mathrm{pA}$ current injection) discharged at a higher frequency in cells from CCI animals (sham: $28.85 \pm 2.83$ $\mathrm{Hz}, n=90$; CCI: $40.70 \pm 4.60 \mathrm{~Hz}, n=86$; $p<0.05$; Fig. $2 G$ ).

We also investigated whether CCI surgery affected the excitability of inhibitory interneurons in L5 of the ACC. The vast majority ( $\sim 90 \%$ ) of interneurons we recorded were FS interneurons (Fig. $3 A, B$ ). There was no difference between the current threshold for AP generation in FS interneurons from sham and CCI animals (sham: $261.82 \pm 18.35 \mathrm{pA}, n=44$; CCI: $253.13 \pm$ $19.89 \mathrm{pA}, n=32, p=0.75$; Fig. $3 C$ ) or in the resting membrane potential (sham: $-65.65 \pm 0.80 \mathrm{mV}, n=44$; CCI: $-66.78 \pm 0.90$ $\mathrm{mV}, p=0.35$; Fig. $3 D$ ). The F-I curves in the two conditions were also similar (Fig. 3E).

\section{CCI causes loss of synaptic connections between pyramidal neurons and FS interneurons}

It has not been investigated so far how functional connectivity in a local cortical microcircuit is affected by peripheral nerve lesion. 
A

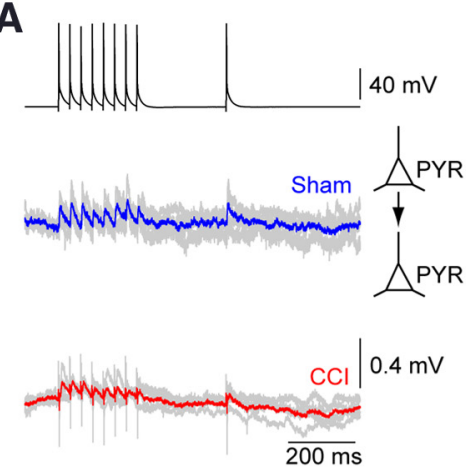

D

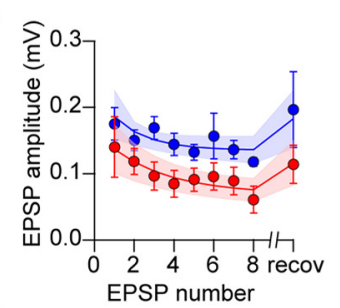

G

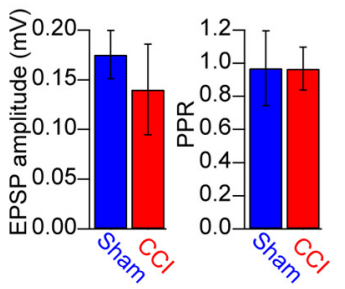

B

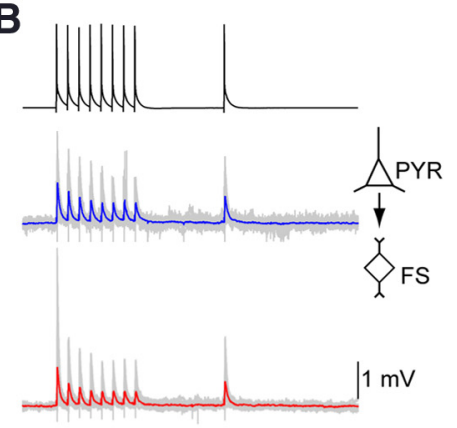

E

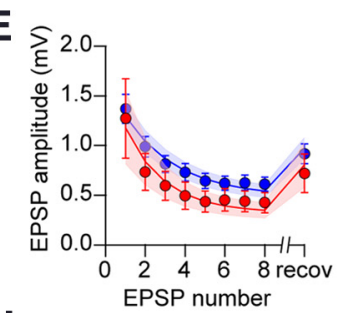

H

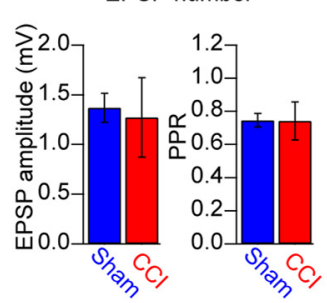

C
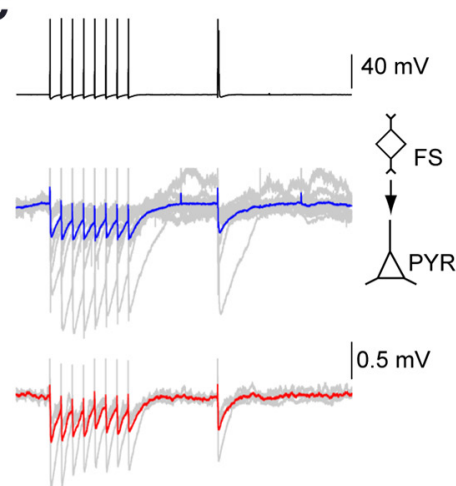

F

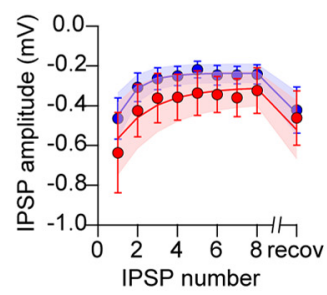

I

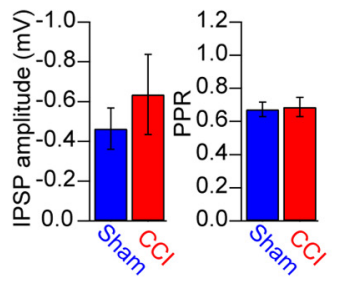

Figure 5. Properties of unitary synaptic connections are not changed after nerve injury. A, Summary of paired recordings from pyramidal to pyramidal neurons in $L 5$ of $A C C$. A train of 8 APs ( 30 $\mathrm{Hz}$ ) followed by one AP $500 \mathrm{~ms}$ later in a presynaptic pyramidal neuron resulted in corresponding EPSPs in the postsynaptic pyramidal neuron. The average postsynaptic response in the sham condition is shown in blue (middle traces) and in the CCI condition in red (lower traces). Traces from individual experiments are shown in gray. $\boldsymbol{B}$, Summary of paired recordings from pyramidal cells to FS interneurons and the corresponding responses to the standard AP pattern. $\boldsymbol{C}$, Same as in $\boldsymbol{B}$ for FS interneuron to pyramidal cell connections. D, Average peak EPSP amplitudes for the pyramidal cell to pyramidal cell connection as a function of EPSP number. Solid lines indicate fits to the average, and shaded areas represent fits to \pm SEM according to the Tsodyks-Markram model. E, Average peak EPSP amplitudes for the pyramidal cell to FS interneuron connection as a function of EPSP number. $\boldsymbol{F}$, Average peak IPSP amplitudes for the FS interneuron to pyramidal cell connection as a function of IPSP number. G-I, Averaged amplitude of the first postsynaptic potential and paired-pulse ratio (PPR) for the different conditions indicating that the unitary connection efficacy was not changed by $\mathrm{CCl}$ surgery. Error bars indicate SEM.

To investigate whether CCI surgery induced circuit rewiring and changes in synaptic properties in L5 of the ACC, we performed whole-cell current-clamp recordings from up to four neurons simultaneously (Fig. 4A,C). Cells were in close proximity with a maximum distance of $100 \mu \mathrm{m}$. We induced a burst of 8 APs at 30 $\mathrm{Hz}$ followed by one AP $500 \mathrm{~ms}$ after the initial AP in the burst in one cell and recorded the synaptic responses (EPSPs or IPSPs) in the other cells (Figs. 4 and 5) (Tsodyks and Markram, 1997). Similar to the medial prefrontal cortex (mPFC) (Rinaldi et al., 2008), connections between L5 pyramidal cells in the ACC were very sparse. In sham animals, we found only 5 connections of 247 tested pairs $(2.02 \%)$. Similarly, in CCI animals, we found 4 connections of 161 tested pairs $(2.48 \%$; Fig. $4 B, E)$. Connections between pyramidal cells and FS interneurons were encountered more frequently. Strikingly, we found a large reduction in the connection probability from pyramidal cells to FS interneurons after CCI surgery. In sham animals, 22 of 81 tested pairs were connected $(27.16 \%)$, whereas only 10 of 76 pairs were connected in CCI animals (13.16\%, $p<0.05$, Fisher's exact test; Fig. $4 D, E)$. The average distance between all tested pyramidal cell and FS interneuron was $50.34 \pm 2.56 \mu \mathrm{m}$ in sham animals and $54.98 \pm$ $2.72 \mu \mathrm{m}$ in CCI animals ( $p=0.217)$. However, when we encountered a connection from a pyramidal cell to an FS interneuron, the cells were in closer proximity in sham animals $(47.26 \pm 4.23$ $\mu \mathrm{m}, n=22)$ than in CCI animals (68.74 $\pm 7.97 \mu \mathrm{m}, n=10, p<$ $0.05)$. This finding might indicate that specifically the synapses between cells that lie close to each other were lost after CCI surgery. This might reflect structural modifications in a cortical microcolumn.

Similarly, connections from FS interneurons to pyramidal cells were also decreased in CCI animals. In sham animals, 17 of 71 tested pairs were connected $(23.94 \%)$; whereas in CCI animals, we found only 6 connections in 71 tested pairs $(8.45 \%, p<$ 0.05 , Fisher's exact test; Fig. $4 D, E$ ). The average distance between all tested FS interneurons and pyramidal cells was $52.10 \pm 7.72$ $\mu \mathrm{m}$ in sham animals and 56.80 $\pm 3.02 \mu \mathrm{m}$ in CCI animals $(p=$ $0.25)$ The distance between connected pairs was not significantly different in the two conditions (sham: $51.21 \pm 4.97 \mu \mathrm{m}, n=17$; CCI: $60.21 \pm 11.13 \mu \mathrm{m}, n=6, p=0.4)$.

Pyramidal cells and FS interneurons were often reciprocally innervated. In both conditions, CCI and sham, an FS interneuron connected to a pyramidal cell, had an $\sim 50 \%$ chance for being targeted by the same pyramidal neuron. The spatial distribution of reciprocally connected cells appeared to be similar to the nonreciprocally connected cells after CCI surgery.

We further analyzed the connected pairs to determine whether CCI surgery induced any changes in the synaptic properties (Fig. 5). We found no significant difference between the 

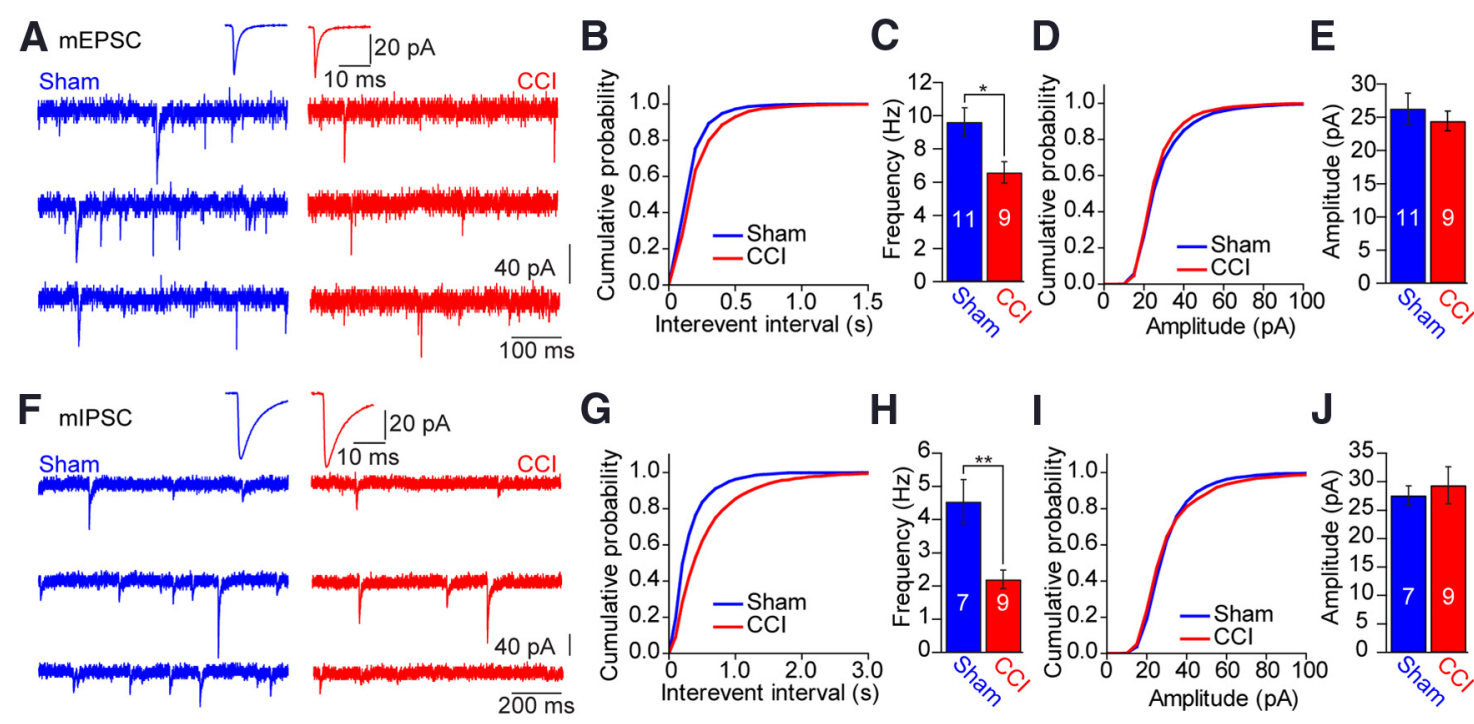

Figure 6. Frequency of mEPSCs and mIPSCs is reduced after nerve injury. A, Example traces showing mEPSCs recorded in $F S$ interneurons in $L 5$ of $A C C$ for sham (left) and CCI (right). Average $\mathrm{mEPSC}$ are shown above the traces. $\boldsymbol{B}$, Cumulative probability plot for the interevent interval for mEPSCs. C, Average mEPSC frequency for the two conditions. $\boldsymbol{D}$, Cumulative probability plot for $\mathrm{mEPSC}$ amplitudes. $\boldsymbol{E}$, Average mEPSC amplitude for the two conditions. $\boldsymbol{F}$, Example traces showing mIPSCs recorded in pyramidal neurons in L5 of ACC for sham (left) and CCI (right). Average mIPSCS are shown above the traces. $\mathbf{G}$, Cumulative probability plot for the interevent interval for mIPSCS. $\boldsymbol{H}$, Average mIPSC frequency for the two conditions. I, Cumulative probability plot for mIPSC amplitudes. J, Average mIPSC amplitude for the two conditions. Numbers in bar graphs indicate number of cells. Error bars indicate SEM. ${ }^{*} p<0.05$. ${ }^{* *} p<0.01$.

EPSP and IPSP amplitudes of either pyramidal cell-pyramidal cell connections, pyramidal cell-FS interneuron connections, or FS interneuron-pyramidal cell connections. Furthermore, the paired-pulse ratio as well as the synaptic depression dynamics to multiple stimulations were not significantly different in the two conditions (Fig. 5).

The loss of unitary synaptic connections found by mapping connection probability in L 5 of ACC might only represent a fraction of the synaptic drive onto cells in this layer. To investigate whether there was a more global reduction in the amount of incoming excitatory signals to the FS interneurons, we recorded mEPSCs from FS interneurons in L5 of the ACC in the presence of $1 \mu \mathrm{M}$ TTX and $1 \mu \mathrm{M}$ GABAzine. In FS interneurons from sham animals, we found an average mEPSC frequency of $9.63 \pm 0.85$ $\mathrm{Hz}(n=11)$. The mEPSC frequency in interneurons from CCI animals was significantly reduced compared with sham animals, with an average mEPSC frequency of $6.59 \pm 0.64 \mathrm{~Hz}(n=9, p<$ 0.05 ; Fig. $6 A-C$ ). We found no change in the mEPSC amplitude (sham: $26.32 \pm 2.31 \mathrm{pA}$, CCI: $24.44 \pm 1.50 \mathrm{pA}, p=0.52$; Fig. $6 D, E)$ or the mEPSP kinetics (data not shown). We also investigated the overall incoming inhibitory events onto pyramidal neurons by recording mIPSCs from pyramidal neurons in L5 of the ACC in the presence of $1 \mu \mathrm{M}$ TTX, $10 \mu \mathrm{M}$ CNQX, and $50 \mu \mathrm{M}$ APV. In pyramidal neurons from sham animals, the mIPSC frequency was $4.55 \pm 0.66 \mathrm{~Hz}(n=7)$. The mIPSC frequency in CCI animals was significantly lower $(2.20 \pm 0.28 \mathrm{~Hz}, n=9, p<0.01$; Fig. $6 \mathrm{~F}-\mathrm{H})$. The mIPSC amplitudes were not significantly different between the two conditions (sham: $27.62 \pm 1.67 \mathrm{pA}$, CCI: $29.36 \pm 3.28$ pA, $p=0.64$; Fig. $6 I, J)$. The measured relative reduction in mEPSC and mIPSC frequency of $32 \%$ and $52 \%$, respectively, correlated well with the estimated reduction of unitary connectivity of $52 \%$ from pyramidal neurons to FS interneurons and 65\% from FS interneurons to pyramidal neurons. The slight underestimation of the loss of connectivity by the frequency measurements suggests that inputs from other layers might be less affected by synaptic remodeling. In conclusion, these results independently confirmed the loss of connectivity between pyramidal and inhibitory neurons in both directions without a change in synaptic properties in L5 of ACC.

\section{Model of the L5 ACC network}

The measured data were complete to reconstruct the local L5 ACC network in a model of recurrently connected pyramidal and FS interneurons (Fig. 7A). For both conditions, we fitted the F-I curves and the neuronal dynamics for the pyramidal and FS interneurons (Fig. $7 B, C$ ), together with the short-term depression of the three types of synaptic connections (Fig. 5). When embedded in the ACC network, the model-pyramidal neurons in the sham condition responded to a constant baseline input current of $200 \mathrm{pA}$ with a low firing rate $(1.7 \mathrm{~Hz})$; whereas in the CCI condition, the firing rate to the same baseline input current was $>4$ times larger (7.5 Hz; Fig. 7D). An additional step input current of $100 \mathrm{pA}$ above baseline to the network for $1 \mathrm{~s}$ (giving a total of 300 $\mathrm{pA}$ ) led to a transient disinhibition because of the depressing synapses of the inhibitory loop and eventually a much higher firing rate of the model-pyramidal neurons in the CCI condition $(17.2 \mathrm{~Hz})$ than for the sham condition $(3 \mathrm{~Hz})$. Consistently with the suppressed inhibitory loop, the stationary firing rate of inhibitory neurons is reduced in the CCI condition (Fig. 7E). These steady-state firing rates as a function of the step input currents are captured by the effective F-I curves, which took the effect of the entire network into account (Fig. $7 F, G$ ). The effective F-I curve of the model-pyramidal neurons in the CCI condition was strongly shifted to the left, indicating increased excitability of the network.

To identify the effect of the various network parameters, we quantified the change in the effective firing rate when changing in the sham condition one single parameter to the CCI condition (Fig. 8A). With an external input current of $300 \mathrm{pA}$, the strongest effect was exerted by the reduced connection probability from the FS interneuron to the pyramidal neurons $\left(p_{I E}\right)$, suggesting that the structural plasticity resulting in cortical disinhibition is a key component for increased excitability of the ACC after nerve injury. For smaller external input currents $(<200 \mathrm{pA})$, the effective F-I curve becomes equally sensitive to the synaptic connectivity from the 
A

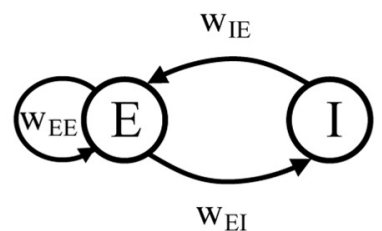

B

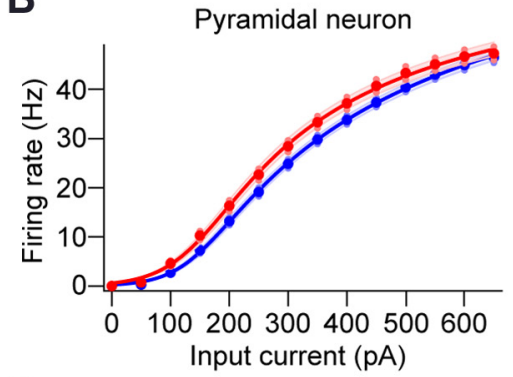

D

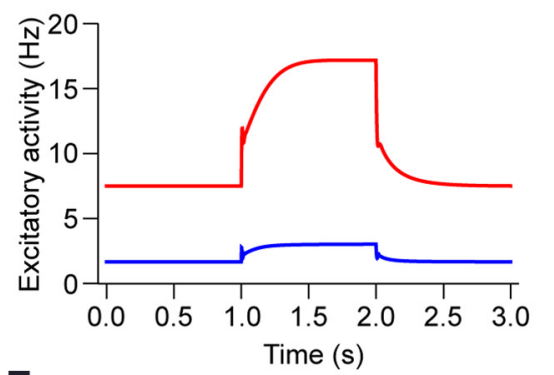

$\mathbf{F}$

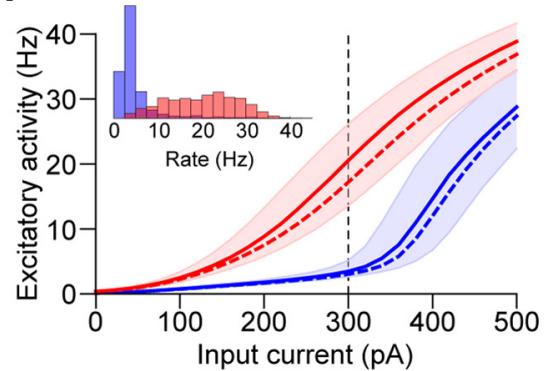

C

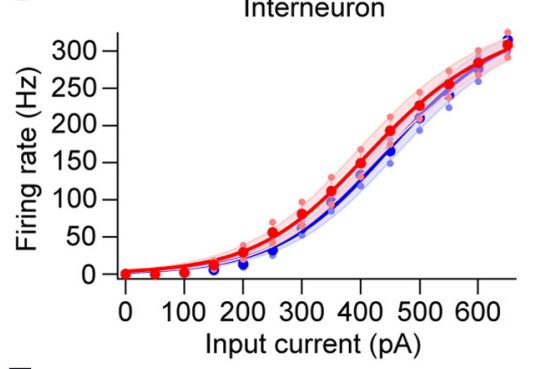

E

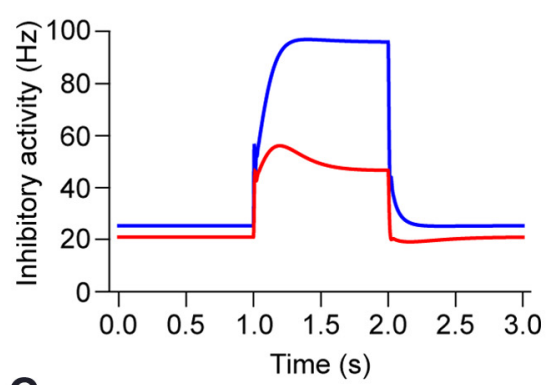

G

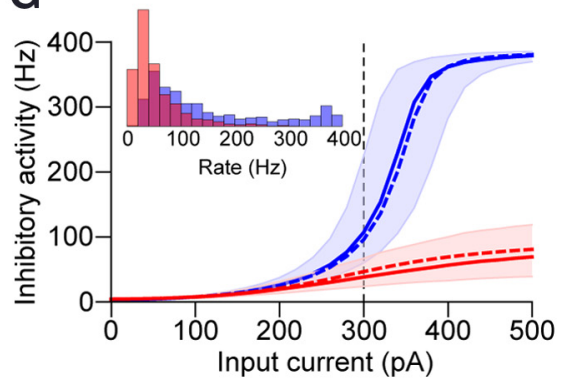

interneurons are striking. These structural changes suggest that the cortical network is disinhibited. A balanced excitation-to-inhibition ratio is critical for information processing and the activity state of neuronal networks. Thus, a loss of connectivity between excitatory and inhibitory neurons could have large effects on circuit behavior and might explain the increased activity observed in the ACC in patients with nerve injury (Hsieh et al., 1995).

\section{Model of the L5 ACC network}

A model of the L5 ACC network corroborated the hypothesis that the loss of connectivity results in disinhibition of the local microcircuit. Our network model is completely based on the experimentally acquired parameters of the cellular and synaptic properties and contains no further assumptions, except on the total number of neurons $(N=1000)$ and the ratio of excitatory and inhibitory cells (0.8). It represents the first attempt to integrate the various plasticity mechanisms induced by nerve injury in ACC and to predict the resulting local network dynamics. The model analysis allowed to quantify the contribution of the individual changes on the overall network effect. Changing the inhibitory-to-excitatory connection probability in the sham model to the CCI value resulted in the largest modification in network excitability. Thus, our model suggests that the loss of inhibitory synapses might have a much larger effect on the network dynamics than the loss of excitatory synapses.

Figure 7. Model of $L 5$ ACC. A, Network architecture. B, C, Calibration of the model. B, F-I curve for pyramidal neurons. C, F-I curve for $\mathrm{FS}$ interneurons in sham (blue) and $\mathrm{Cl}$ (red) conditions. The average F-I curve from the data (large disks) is fitted with the model (solid line). \pm SEM of the data (small disks) are also fitted with the model (shaded area). $\boldsymbol{D}, \boldsymbol{E}$, Response of the network ( $\boldsymbol{D}$, excitatory neurons; $\boldsymbol{E}$, inhibitory neurons) to step current in the pool of excitatory neurons for the sham condition (blue) and for the C Cl condition (red). $\boldsymbol{F}, \mathbf{G}$, Stationary network response ( $\boldsymbol{F}$, excitatory neurons; $\boldsymbol{G}$, inhibitory neurons) to a given excitatory current for the sham condition (blue) and for the $\mathrm{CCl}$ condition (red). The dashed line indicates the effective transfer function for the mean parameters. The solid line indicates the median; the shaded area represents the interval between the first and third quartile when the parameters are sampled consistently with the uncertainty of the mean (see Materials and Methods). Inset, Distribution of responses at $300 \mathrm{pA}$.

pyramidal neurons to the interneurons as well as to the short-term plasticity parameters of the connections form the pyramidal to fast spiking cells (Fig. 8B). Thus, for small input current, no single parameter could account exclusively for the increased excitability of the model network; but for stronger input currents, the increased excitability is mainly the result of the reduced connection probability from FS interneurons to pyramidal cells.

\section{Discussion}

Our results indicate that sciatic nerve injury that causes the development of neuropathic pain results in structural modification of the local microcircuitry in L5 of the ACC. Particularly, the loss of inhibitory synapses onto excitatory pyramidal neurons and the loss of the excitatory drive onto inhibitory FS

\section{Disinhibition in neuropathic pain}

Clinical studies have suggested that complex regional pain syndrome Type I (Lenz et al., 2011), neuropathic pain caused by diabetes mellitus (Turgut and Altun, 2009), or nerve lesions (Lefaucheur et al., 2006) and migraine (Valeriani et al., 2005) induce cortical disinhibition. Preclinical animal models show that altered inhibitory neurotransmission in the dorsal horn of the spinal cord contributes to pathological pain states (Zeilhofer et al., 2012). A loss in synaptic inhibition onto projecting neurons in the dorsal horn has been implicated in the development of inflammatory pain (Knabl et al., 2008). The cellular mechanisms for spinal disinhibition are explained by changes in the intracellular chloride concentration of projecting neurons resulting from a reduction in the expression of the potassiumchloride exporter KCC2 (Coull et al., 2003), a decrease in GABA release probability, or the decrease in the concentration of the GABA synthesizing enzyme glutamic acid decarboxylase (Moore et al., 2002). In the somatosensory cortex, nerve injury results in an increased activity of GABAergic interneurons resulting from increased thalamic drive, which is nevertheless ineffective be- 
A
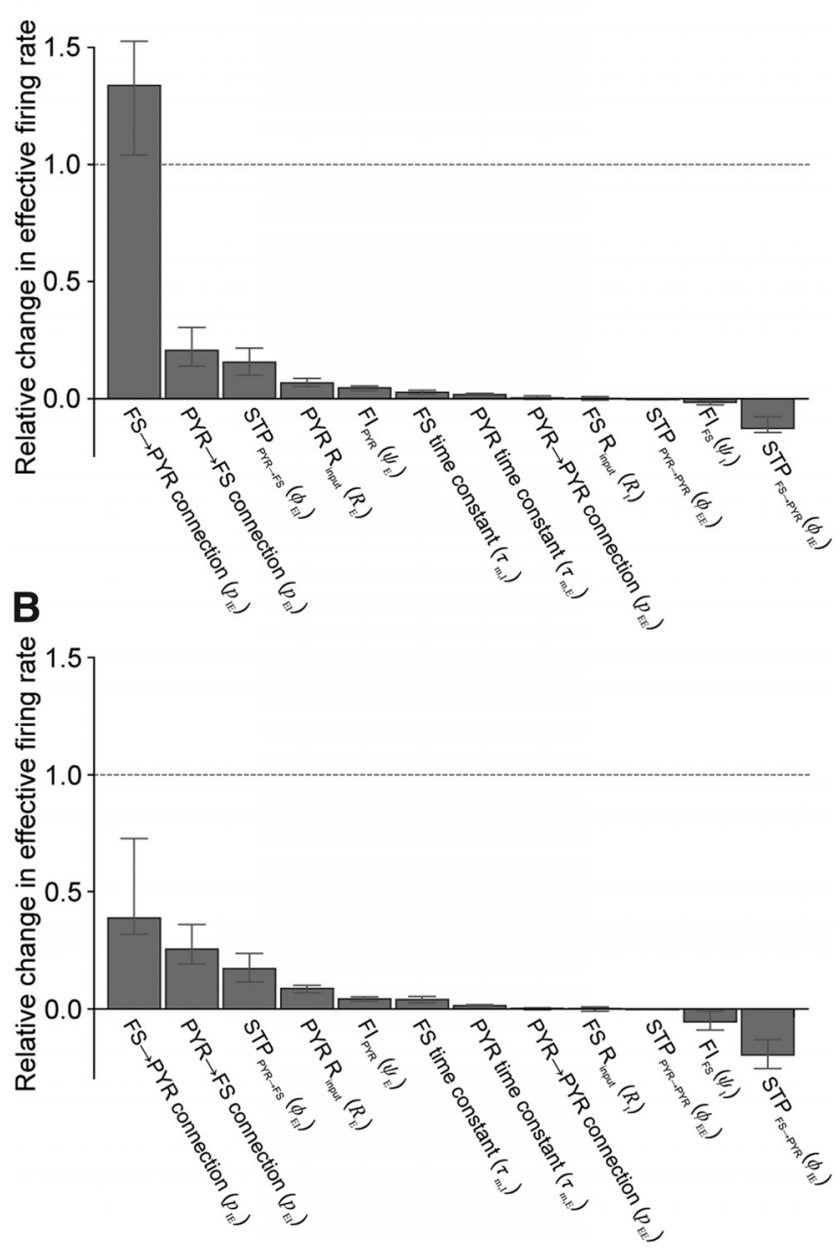

Figure 8. Loss of connectivity is the most prominent factor for the transition from sham to $C \mathrm{CI}$ conditions. $A$, Relative effect of the model parameters (or group of parameters) on the firing rate of the excitatory neurons for a given input current $(300 \mathrm{pA})$. All the parameters are taken from the sham dataset, except the parameter under investigation, which is taken from the $\mathrm{CCl}$ dataset (for a formal definition of this relative effect, see Materials and Methods). $\boldsymbol{B}$, Same as in $A$ for a given input current of $\mathrm{I}=150 \mathrm{pA}$.

cause of a change in KCC2 expression in excitatory pyramidal neurons (Eto et al., 2012). Thus, disinhibition of pain circuits appears to be a fundamental mechanism in the development of chronic pain.

\section{Cellular mechanisms for the loss of connectivity}

The precise cellular mechanisms underlying the marked reduction in connectivity after nerve injury remain to be elucidated. Moreover, the signaling cascades involved in inhibitory plasticity are not well established (Kullmann et al., 2012; Sieber et al., 2013). Spine and bouton motility is regulated by sensory experience and can occur rapidly in cortical networks (Le Bé and Markram, 2006). Such a structural remodeling can lead to either the stabilization or destabilization of synaptic connections depending on the activity patterns (Kasai et al., 2010). The induction of LTD, for example, can lead to the retraction of synaptic connections (Nägerl et al., 2004; Zhou et al., 2004).

On the network level, the properties of local intracortical inhibitory circuits can be modified by altered sensory experience (Chen et al., 2011, 2012). Whisker deprivation results in cortical disinhibition gating the induction of LTP at synapses from sur- round whiskers onto cells responsive for the principle whisker (Gambino and Holtmaat, 2012). In the visual cortex, removal of visual input correlates with a rapid and long-lasting reduction in the number of dendritic spines and axonal boutons on inhibitory neurons (Keck et al., 2011). Furthermore, nerve injury causes an increase in dendritic complexity and spine density in basal dendrites in L2/L3 of the MPFC (Metz et al., 2009). Dendritic branches of cortical interneurons are particularly dynamic, undergoing a range of structural changes over short time-scales, even in the absence of sensory stimulation (Lee et al., 2006). Thus, peripheral nerve damage might promote such mechanisms.

\section{Plasticity of intrinsic excitability and synaptic strength}

We also find that nerve injury causes potentiation of intrinsic excitability in L5 pyramidal neurons in the ACC. LTP of intrinsic excitability can be induced experimentally in naive animals by high-frequency stimulation (Cudmore and Turrigiano, 2004). It is possible that this form of plasticity occurs as a result of increased activity in the ACC that is caused by enhanced afferent input after nerve injury. In contrast, the AP current threshold of L2/3 pyramidal cells in the ACC is not altered, but a subclass of cells shows a higher initial spike frequency (Cao et al., 2009). Similarly, nerve injury does not change the excitability of L2/3 neurons in the prelimbic area of the mPFC (Metz et al., 2009). Thus, changes in intrinsic excitability in response to nerve injury might be confined to pyramidal neurons of L5 in the ACC.

Several reports have demonstrated plasticity of synaptic transmission strength in the ACC in animal models of chronic pain, in contrast to the results presented here. In L2/3 pyramidal neurons of the ACC, both increased postsynaptic responsiveness and increased presynaptic transmitter release probability have been observed in mice with peripheral nerve ligation (Xu et al., 2008). Recently, protein kinase $\mathrm{M} \zeta$, a kinase responsible for maintaining late-phase LTP, has been suggested to maintain pain-induced plasticity in L2/3 pyramidal neurons of the ACC (Li et al., 2010). Blocking this kinase in the ACC can alleviate mechanical hyperalgesia to some extent. Furthermore, the decrease of synaptic strength in the form of LTD is also altered in the ACC during chronic pain conditions (Wei et al., 1999; Chiou et al., 2012; Kang et al., 2012).

Further experiments are required to determine the source of input to the ACC and the activity patterns that induce the described forms of plasticity. The changes in pyramidal neuron excitability and connectivity that we observe may be the result of changes in thalamocortical rhythms. Studies of neuropathic pain in both humans and animals have established a relationship between pain and thalamocortical dysrhythmia (Shyu and Vogt, 2009). The ACC receives thalamic input from the midline, mediodorsal, and intralaminar thalamic nuclei, and altered activity in these nuclei might induce plasticity in the ACC (Shyu and Vogt, 2009). Another potential source of input is the primary somatosensory cortex, which is also modified in neuropathic pain. The activity in somatosensory cortex can strongly influence neuronal activity in the ACC (Eto et al., 2011). Thus, the cause and effect of the observed changes have to be determined for a better understanding of the development of neuropathic pain.

\section{Placement in the context of ACC function and clinical implications}

The ACC is of particular importance for the perception and evaluation of the unpleasantness of pain. It is an integral part of the limbic system and central for processing emotional aspects of pain (Vogt, 2005). Patients with severe chronic pain that have 
undergone cingulumotomy report that they can still feel the noxious stimuli, but it is no longer particularly bothersome (Foltz and White, 1962). Beyond the strong connectivity to other limbic areas, excitatory activity in the ACC produces facilitation of spinal nociceptive reflexes, likely conveyed through the periaqueductal gray and rostral ventral medulla (Calejesan et al., 2000). The ACC might therefore be part of a positive feedback control system that enhances nociceptive transmission in the spinal cord. Disinhibition and increased activity in the ACC could therefore facilitate increased pain transmission from subcortical regions.

The "pain matrix," including the ACC, is consistently activated by acute experimental pain in control subjects. However, conflicting results exist on whether these areas are involved in pathological chronic pain syndromes. Several studies have failed to detect activation of the ACC during brush-evoked allodynia in neuropathic pain patients, but there are also studies that show the opposite (Moisset and Bouhassira, 2007). Hsieh et al. (1995) conducted a PET study of ongoing pain in patients with painful mononeuropathy using regional cerebral blood flow as a readout for neuronal activity. PET scans were acquired before and after regional nerve block with lidocaine. They observed decreased activity in the anterior insula, the posterior parietal cortex, the inferior and lateral prefrontal cortex, and the ACC after lidocaine treatment, indicating that the initial levels of regional cerebral blood flow were abnormally high. No changes were observed in the somatosensory cortices. These data suggest that chronic continuous pain is primarily related to changes in areas involved in the affective and emotional dimension of pain rather than with the areas involved in the sensory components of pain processing. High neuronal activity in the ACC of neuropathic pain patients corresponds well with our results in mice.

In conclusion, we show that nerve injury causes changes in intrinsic excitability in L5 pyramidal neurons of the ACC and a loss of local bidirectional connections between pyramidal cells and FS interneurons, eventually resulting in cortical disinhibition. Yet, only the altered connectivity pattern has a significant effect on the network dynamics. We therefore suggest that these network changes are an important factor for the establishment of a "pain memory" in the ACC. Restoring normal activity in the ACC could therefore potentially remove the unpleasantness of pain (Johansen and Fields, 2004; Qu et al., 2011). The new insights in ACC plasticity after nerve injury provided here may pave the way for new strategies to relieve chronic pain.

\section{References}

Apkarian AV, Baliki MN, Geha PY (2009) Towards a theory of chronic pain. Prog Neurobiol 87:81-97. CrossRef Medline

Basbaum AI, Bautista DM, Scherrer G, Julius D (2009) Cellular and molecular mechanisms of pain. Cell 139:267-284. CrossRef Medline

Bennett GJ, Xie YK (1988) A peripheral mononeuropathy in rat that produces disorders of pain sensation like those seen in man. Pain 33:87-107. CrossRef Medline

Breivik H, Collett B, Ventafridda V, Cohen R, Gallacher D (2006) Survey of chronic pain in Europe: prevalence, impact on daily life, and treatment. Eur J Pain 10:287-333. CrossRef Medline

Calejesan AA, Kim SJ, Zhuo M (2000) Descending facilitatory modulation of a behavioral nociceptive response by stimulation in the adult rat anterior cingulate cortex. Eur J Pain 4:83-96. CrossRef Medline

Cao XY, Xu H, Wu LJ, Li XY, Chen T, Zhuo M (2009) Characterization of intrinsic properties of cingulate pyramidal neurons in adult mice after nerve injury. Mol Pain 5:73. CrossRef Medline

Chen JL, Lin WC, Cha JW, So PT, Kubota Y, Nedivi E (2011) Structural basis for the role of inhibition in facilitating adult brain plasticity. Nat Neurosci 14:587-594. CrossRef Medline

Chen JL, Villa KL, Cha JW, So PT, Kubota Y, Nedivi E (2012) Clustered dynamics of inhibitory synapses and dendritic spines in the adult neocortex. Neuron 74:361-373. CrossRef Medline

Chiou CS, Huang CC, Liang YC, Tsai YC, Hsu KS (2012) Impairment of long-term depression in the anterior cingulate cortex of mice with bone cancer pain. Pain 153:2097-2108. CrossRef Medline

Costigan M, Scholz J, Woolf CJ (2009) Neuropathic pain: a maladaptive response of the nervous system to damage. Annu Rev Neurosci 32:1-32. CrossRef Medline

Coull JA, Boudreau D, Bachand K, Prescott SA, Nault F, Sík A, De Koninck P, De Koninck Y (2003) Trans-synaptic shift in anion gradient in spinal lamina I neurons as a mechanism of neuropathic pain. Nature 424:938 942. CrossRef Medline

Cudmore RH, Turrigiano GG (2004) Long-term potentiation of intrinsic excitability in LV visual cortical neurons. J Neurophysiol 92:341-348. CrossRef Medline

Devinsky O, Morrell MJ, Vogt BA (1995) Contributions of anterior cingulate cortex to behaviour. Brain 118:279-306. CrossRef Medline

Eto K, Wake H, Watanabe M, Ishibashi H, Noda M, Yanagawa Y, Nabekura J (2011) Inter-regional contribution of enhanced activity of the primary somatosensory cortex to the anterior cingulate cortex accelerates chronic pain behavior. J Neurosci 31:7631-7636. CrossRef Medline

Eto K, Ishibashi H, Yoshimura T, Watanabe M, Miyamoto A, Ikenaka K, Moorhouse AJ, Nabekura J (2012) Enhanced gabaergic activity in the mouse primary somatosensory cortex is insufficient to alleviate chronic pain behavior with reduced expression of neuronal potassium-chloride cotransporter. J Neurosci 32:16552-16559. CrossRef Medline

Fields H (2004) State-dependent opioid control of pain. Nat Rev Neurosci 5:565-575. CrossRef Medline

Foerster BR, Petrou M, Edden RA, Sundgren PC, Schmidt-Wilcke T, Lowe SE, Harte SE, Clauw DJ, Harris RE (2012) Reduced insular $\gamma$-aminobutyric acid in fibromyalgia. Arthritis Rheum 64:579-583. CrossRef Medline

Foltz EL, White LE Jr (1962) Pain “relief” by frontal cingulumotomy. J Neurosurg 19:89-100. CrossRef Medline

Gambino F, Holtmaat A (2012) Spike-timing-dependent potentiation of sensory surround in the somatosensory cortex is facilitated by deprivationmediated disinhibition. Neuron 75:490-502. CrossRef Medline

Henderson LA, Peck CC, Petersen ET, Rae CD, Youssef AM, Reeves JM, Wilcox SL, Akhter R, Murray GM, Gustin SM (2013) Chronic pain: lost inhibition? J Neurosci 33:7574-7582. CrossRef Medline

Hsieh JC, Belfrage M, Stone-Elander S, Hansson P, Ingvar M (1995) Central representation of chronic ongoing neuropathic pain studied by positron emission tomography. Pain 63:225-236. CrossRef Medline

Johansen JP, Fields HL (2004) Glutamatergic activation of anterior cingulate cortex produces an aversive teaching signal. Nat Neurosci 7:398-403. CrossRef Medline

Johansen JP, Fields HL, Manning BH (2001) The affective component of pain in rodents: direct evidence for a contribution of the anterior cingulate cortex. Proc Natl Acad Sci U S A 98:8077-8082. CrossRef Medline

Kang SJ, Liu MG, Chen T, Ko HG, Baek GC, Lee HR, Lee K, Collingridge GL, Kaang BK, Zhuo M (2012) Plasticity of metabotropic glutamate receptor-dependent long-term depression in the anterior cingulate cortex after amputation. J Neurosci 32:11318-11329. CrossRef Medline

Kasai H, Fukada M, Watanabe S, Hayashi-Takagi A, Noguchi J (2010) Structural dynamics of dendritic spines in memory and cognition. Trends Neurosci 33:121-129. CrossRef Medline

Keck T, Scheuss V, Jacobsen RI, Wierenga CJ, Eysel UT, Bonhoeffer T, Hübener M (2011) Loss of sensory input causes rapid structural changes of inhibitory neurons in adult mouse visual cortex. Neuron 71:869-882. CrossRef Medline

Kim SK, Nabekura J (2011) Rapid synaptic remodeling in the adult somatosensory cortex following peripheral nerve injury and its association with neuropathic pain. J Neurosci 31:5477-5482. CrossRef Medline

Knabl J, Witschi R, Hösl K, Reinold H, Zeilhofer UB, Ahmadi S, Brockhaus J, Sergejeva M, Hess A, Brune K, Fritschy JM, Rudolph U, Möhler H, Zeilhofer HU (2008) Reversal of pathological pain through specific spinal GABAA receptor subtypes. Nature 451:330-334. CrossRef Medline

Kullmann DM, Moreau AW, Bakiri Y, Nicholson E (2012) Plasticity of inhibition. Neuron 75:951-962. CrossRef Medline

Le Bé, JV, Markram H (2006) Spontaneous and evoked synaptic rewiring in the neonatal neocortex. Proc Natl Acad Sci U S A 103:13214-13219. CrossRef Medline

Lee WC, Huang H, Feng G, Sanes JR, Brown EN, So PT, Nedivi E (2006) 
Dynamic remodeling of dendritic arbors in gabaergic interneurons of adult visual cortex. PLoS Biol 4:e29. CrossRef Medline

Lefaucheur JP, Drouot X, Ménard-Lefaucheur I, Keravel Y, Nguyen JP (2006) Motor cortex RTMS restores defective intracortical inhibition in chronic neuropathic pain. Neurology 67:1568-1574. CrossRef Medline

Lenz M, Höffken O, Stude P, Lissek S, Schwenkreis P, Reinersmann A, Frettlöh J, Richter H, Tegenthoff M, Maier C (2011) Bilateral somatosensory cortex disinhibition in complex regional pain syndrome type I. Neurology 77:1096-1101. CrossRef Medline

Letzkus JJ, Wolff SB, Meyer EM, Tovote P, Courtin J, Herry C, Lüthi A (2011) A disinhibitory microcircuit for associative fear learning in the auditory cortex. Nature 480:331-335. CrossRef Medline

Li XY, Ko HG, Chen T, Descalzi G, Koga K, Wang H, Kim SS, Shang Y, Kwak C, Park SW, Shim J, Lee K, Collingridge GL, Kaang BK, Zhuo M (2010) Alleviating neuropathic pain hypersensitivity by inhibiting PKMzeta in the anterior cingulate cortex. Science 330:1400-1404. CrossRef Medline

McDonald AJ, Mascagni F, Guo L (1996) Projections of the medial and lateral prefrontal cortices to the amygdala: a phaseolus vulgaris leucoagglutinin study in the rat. Neuroscience 71:55-75. CrossRef Medline

Metz AE, Yau HJ, Centeno MV, Apkarian AV, Martina M (2009) Morphological and functional reorganization of rat medial prefrontal cortex in neuropathic pain. Proc Natl Acad Sci U S A 106:2423-2428. CrossRef Medline

Moisset X, Bouhassira D (2007) Brain imaging of neuropathic pain. Neuroimage 37[Suppl 1]:S80-S88.

Moore KA, Kohno T, Karchewski LA, Scholz J, Baba H, Woolf CJ (2002) Partial peripheral nerve injury promotes a selective loss of GABAergic inhibition in the superficial dorsal horn of the spinal cord. J Neurosci 22:6724-6731. Medline

Murayama M, Pérez-Garci E, Nevian T, Bock T, Senn W, Larkum ME (2009) Dendritic encoding of sensory stimuli controlled by deep cortical interneurons. Nature 457:1137-1141. CrossRef Medline

Nägerl UV, Eberhorn N, Cambridge SB, Bonhoeffer T (2004) Bidirectional activity-dependent morphological plasticity in hippocampal neurons. Neuron 44:759-767. CrossRef Medline

Neugebauer V, Li W, Bird GC, Han JS (2004) The amygdala and persistent pain. Neuroscientist 10:221-234. CrossRef Medline

Pandya DN, Van Hoesen GW, Mesulam MM (1981) Efferent connections of the cingulate gyrus in the rhesus monkey. Exp Brain Res 42:319-330. Medline

Paxinos G, Watson C (1997) The rat brain in stereotaxic coordinates. San Diego: Academic.

Qu C, King T, Okun A, Lai J, Fields HL, Porreca F (2011) Lesion of the rostral anterior cingulate cortex eliminates the aversiveness of spontaneous neuropathic pain following partial or complete axotomy. Pain 152: 1641-1648. CrossRef Medline
Rinaldi T, Perrodin C, Markram H (2008) Hyper-connectivity and hyperplasticity in the medial prefrontal cortex in the valproic acid animal model of autism. Front Neural Circuits 2:4. CrossRef Medline

Saab CY (2012) Pain-related changes in the brain: diagnostic and therapeutic potentials. Trends Neurosci 35:629-637. CrossRef Medline

Shyu BC, Vogt BA (2009) Short-term synaptic plasticity in the nociceptive thalamic-anterior cingulate pathway. Mol Pain 5:51. CrossRef Medline

Sieber AR, Min R, Nevian T (2013) Non-hebbian long-term potentiation of inhibitory synapses in the thalamus. J Neurosci 33:15675-15685. CrossRef Medline

Treede RD, Kenshalo DR, Gracely RH, Jones AK (1999) The cortical representation of pain. Pain 79:105-111. CrossRef Medline

Tsodyks MV, Markram H (1997) The neural code between neocortical pyramidal neurons depends on neurotransmitter release probability. Proc Natl Acad Sci U S A 94:719-723. CrossRef Medline

Turgut N, Altun BU (2009) Cortical disinhibition in diabetic patients with neuropathic pain. Acta Neurol Scand 120:383-388. CrossRef Medline

Valeriani M, Rinalduzzi S, Vigevano F (2005) Multilevel somatosensory system disinhibition in children with migraine. Pain 118:137-144. CrossRef Medline

Vogt BA (2005) Pain and emotion interactions in subregions of the cingulate gyrus. Nat Rev Neurosci 6:533-544. CrossRef Medline

Wei F, Li P, Zhuo M (1999) Loss of synaptic depression in mammalian anterior cingulate cortex after amputation. J Neurosci 19:9346-9354. Medline

Woolf CJ, Salter MW (2000) Neuronal plasticity: increasing the gain in pain. Science 288:1765-1769. CrossRef Medline

Wyss JM, Sripanidkulchai K (1984) The topography of the mesencephalic and pontine projections from the cingulate cortex of the rat. Brain Res 293:1-15. CrossRef Medline

Xu H, Wu LJ, Wang H, Zhang X, Vadakkan KI, Kim SS, Steenland HW, Zhuo M (2008) Presynaptic and postsynaptic amplifications of neuropathic pain in the anterior cingulate cortex. J Neurosci 28:7445-7453. CrossRef Medline

Zeilhofer HU, Benke D, Yevenes GE (2012) Chronic pain states: pharmacological strategies to restore diminished inhibitory spinal pain control. Annu Rev Pharmacol Toxicol 52:111-133. CrossRef Medline

Zhou Q, Homma KJ, Poo MM (2004) Shrinkage of dendritic spines associated with long-term depression of hippocampal synapses. Neuron 44: 749-757. CrossRef Medline

Zhuo M (2008) Cortical excitation and chronic pain. Trends Neurosci 31: 199-207. CrossRef Medline

Ziemann U, Rothwell JC, Ridding MC (1996) Interaction between intracortical inhibition and facilitation in human motor cortex. J Physiol 496: 873-881. Medline 